\title{
COMPARATIVE STUDY BETWEEN ULTRASOUND GUIDED QUADRATUS LUMBORUM BLOCK VERSUS ULTRASOUND GUIDED TRANSVERSUS ABDOMINIS PLANE BLOCK FOR POSTOPERATIVE PAIN RELIEF IN PATIENTS UNDERGOING UNILATERAL INGUINAL SURGERIES
}

By

\section{Ali Mohamed Ali Esmail*, Tarek Abd El-Salam Seleem, Essam Shafiq Mohammad, and Mostafa Mohamed Mohamed El-Sayed}

Anesthesia and Intensive Care Department, Faculty of Medicine, Cairo, Al-Azhar University

*Corresponding author: Ali Mohamed Ali Esmail, E-mail: ali_esmail2014@yahoo.com

\begin{abstract}
Background: An effective pain therapy to block or modify the physiologic responses to stress has become an essential component of anesthesia for adequate postoperative pain relief.

Objectives: Assessment of the postoperative analgesic efficacy of ultrasound guided quadratus lumborum block compared with transversus abdominis plane block in unilateral inguinal surgeries by measuring total amount of analgesic consumption over 24 hours.

Patients and Methods: After approval of scientific and ethical committees in Al-Azhar University Hospitals, ninety patients were included in the study, and were divided into three equal groups: quadratus lumborum block (QLB) group, transversus abdominis plane block (TAP) group and control group. The following data were carried out: vital signs, visual analogue scale, time of first analgesia required by the patient, total amount of analgesia consumption and patient satisfaction score.

Results: The QLB was the most effective technique in providing analgesia after unilateral inguinal surgeries without associated hemodynamic instability in comparison to TAP block and intravenous systemic analgesia. TAP block had the ability to provide an intermediate option between intravenous systemic analgesia and QLB when QLB could not be performed.

Conclusion: Ultrasound guided quadratus lumborum and transversus abdominis plane blocks provide effective modality for control of postoperative pain associated with unilateral inguinal surgeries with superiority of quadratus lumborum block to transversus abdominis plane block for control of postoperative pain. However, TAP block still technically easier than QL block.
\end{abstract}

Keywords: Ultrasound Guided, Quadratus Lumborum block, Transversus Abdominis Plane Block, Postoperative Pain, inguinal surgeries. 


\section{INTRODUCTION}

Postoperative pain is a major obstacle for early postoperative ambulation. It increases the risk of venous thromboembolism and respiratory complications and prolongs hospital stay. Inadequately treated postoperative pain may lead to chronic pain. A higher incidence of chronic postsurgical pain has been reported after a flank incision. Opioids are the most commonly used analgesics in the perioperative period, which provide analgesia but have their own side effects. Therefore, use of a multimodal analgesic strategy is very important. Regional anesthesia and analgesia has shown to provide excellent analgesia and also provide benefits, which extend beyond the perioperative period (Owen et al., 2010).

The transversus abdominis plane (TAP) block is already established as a part of the multimodal approach to pain relief for abdominal surgical procedures (Owen et al., 2011). Rafi (2001) originally described the transversus abdominis plane (TAP) block by the landmark technique. This description was proposed as an alternative to the traditional abdominal field block, which frequently involved multiple injection sites and potentially toxic doses of local anesthetic; incorrect needle tip placement has been associated with block failure and concern for potential patient harm (Børglum and Jensen, 2012). Because TAP blockade is limited to somatic anesthesia of the abdominal wall and highly dependent on interfacial spread, various newer techniques have been proposed to enhance analgesia, either in addition to TAP block or as a single modality. In particular, variants of quadratus lumborum blocks (QLBs) have been proposed as more consistent methods with an aim to accomplish somatic as well as visceral analgesia of the abdomen (El-Sharkawy, 2017).

The quadratus lumborum block (QLB) was first described by Blanco in 2007. The main advantages of QLB compared to transversus abdominis plane block is the extensions of local anesthetic agent beyond the transversus abdominis plane to thoracic paravertebral space. The wider spread of the local anesthetic agents may produce extensive analgesia and prolonged action of injected local anesthetic solution (Blanco et al., 2015).

This work aimed to study the postoperative analgesic efficacy of ultrasound guided quadratus lumborum block compared with transversus abdominis plane block in unilateral inguinal surgeries by measuring analgesic consumption over 24 hours as a primary outcome and by measuring visual analogue scale and time of first analgesic request as a secondary outcome.

\section{PATIENTS AND METHODS}

After approval of local scientific and ethical anesthetic committees and informed written consents from the patients, this controlled prospective randomized double blinded clinical trial was conducted at Al-Azhar University Hospitals. Ninety male patients scheduled for elective unilateral inguinal surgeries were randomized into 3 equal groups: Transverses Abdominis Plane block group (TAP Group), Quadratus lumborum block group (QLB Group) and group with general anesthesia only (Control group). 
- TAP Group: All members received transversus abdominis plane block guided by ultrasound followed by induction of general anesthesia.

- QLB Group: All members received quadratus lumborum block guided by ultrasound followed by induction of general anesthesia.

- Control Group: All members received general anesthesia only.

The patients included in this study were adult males between age of 18 and 65 years old with American Society of Anesthesiologists (ASA) class I and II, body mass index [BMI]: $<30 \mathrm{~kg} / \mathrm{m}^{2}$. Scheduled for elective unilateral inguinal surgeries like inguinal hernia, hydrocele, varicocele.

All patients with known
hypersensitivity to study drugs, emergency operations, coagulation disorders or thrombocytopenia, infection at the site of needle insertion, further refusal to participate in the study, inability to comprehend or use the visual analogue scoring system, diabetes to exclude evidence of peripheral neuropathy, chronic pain syndrome, were excluded from the study.

Evaluation of the patients was carried out on the day before surgery through proper history taking, clinical examination and laboratory investigations. Chest $\mathrm{X}$ ray and ECG were done for patients above 40 years or his complaint of respiratory or cardiac problems. All patients was informed with the procedure of US guided TAP block or US guided QLB ,and they were trained to use the visual analogue scale (VAS) which consisted of $10 \mathrm{~cm}$ line, 0 equivalent to no pain and 10 denoting the worst imaginable pain. They were trained also to use the patient satisfactory scores.

On arrival to the operative theatre, a peripheral venous catheter was inserted in all patients; multichannel monitor was attached to the patient to display ECG (lead II), heart rate (beats/min), noninvasive mean arterial blood pressure $(\mathrm{mmHg})$ and oxygen saturation $\left(\mathrm{SpO}_{2}\right)$. All patients received midazolam $(0.02 \mathrm{mg} / \mathrm{kg})$ intravenously together with ranitidine (50 $\mathrm{mg}, \quad \mathrm{IV}), \quad$ and metoclopramide $(10 \mathrm{mg}$, IV) as premedication 10 minutes before performance of the block.

In the TAP group, the patients in the supine position, a high-frequency linear probe was positioned laterally toward the anterolateral part of the abdominal wall midway between the iliac crest and the subcostal margin. The injec $\neg$ tion site was defined between aponeurosis of internal oblique and transversus abdominis muscles. When the tip correctly located in the targeted plane, bupivacaine $(0.25 \% 0.3$ $\mathrm{ml} / \mathrm{kg}$ ), injected with intermittent aspira $\neg$ tion. The correct placement of the needle confirmed by separation of these two muscles (Chin et al., 2017).

In the QLB group, the patient was in the lateral position. A low-frequency convex probe was vertically attached above the iliac crest and a needle was inserted in the plane from the posterior edge of the convex probe through the QL in an anteromedial direction. The needle tip was placed between the PM muscle and the QL muscle and bupivacaine

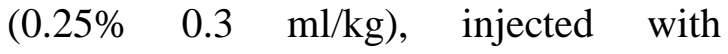
intermittent aspiration. The correct placement of the needle confirmed by the 
local anesthetic appeared to press down the PM in the ultrasound image (Ueshima et al., 2013).

All patients in the three groups received standard general anesthesia, induction of general anesthesia was done by fentanyl (1 $\mu \mathrm{g} / \mathrm{kg}, \quad \mathrm{IV})$, propofol $(2 \mathrm{mg} / \mathrm{Kg}, \quad \mathrm{IV}), \quad$ and Cis-atracurium $(0.15 \mathrm{mg} / \mathrm{Kg}, \mathrm{IV})$ to facilitate endotracheal intubation. Maintenance of anesthesia obtained with $1.5 \%$ Isoflurane in $100 \%$ $\mathrm{O}_{2}$. At the end of the operation, the patients were extubated after taking good regular tidal volume.

The following data were carried out: patient demographic data including age, sex, weight, type and duration of surgery. Also, heart rate (beats/min), mean arterial blood pressure $(\mathrm{mmHg})$, and oxygen saturation $\left(\mathrm{SpO}_{2} \%\right)$ were recorded before induction of anesthesia, every 15 minutes intraoperatively, and in PACU (post anesthesia care unit, i.e. recovery room), then at 1, 2, 3, 4, 8, 12, 16 and 24 hours postoperatively. Respiratory rate was recorded before induction and in PACU, then at 1, 2, 3, 4, 8, 12, 16 and 24 hours postoperatively. Onset of sensory block at T10 was assessed every 3 minutes till block was stabilized by loss of cold sensation to ice cup. The adequacy of block T10-L1 was determined before induction of anesthesia.

Acute postoperative somatic and visceral pain within the first 24 hours postoperatively was assessed by using visual analogue scale $(0-10)$ where $0=$ no pain, 1-2=mild pain, 3-4=moderate pain, $5-6=$ severe pain, $7-8=$ very severe pain, $10=$ worst pain at PACU and postoperative patient room at 1, 2, 3, 4, 8, 12, 16 and 24 hours postoperatively. In the 3 groups, all patients had VAS $\geq 3$ received IV Ketorolac $30 \mathrm{mg}$ (not to exceed 120 $\mathrm{mg} /$ day), then VAS was reassessed 15 minutes later, morphine $(0.05 \mathrm{mg} / \mathrm{kg}$ IV) was given if (VAS) $\geq 3$ after giving Ketorolac. VAS reassessed 15 minutes later to any rescue pain by supplementation of morphine $(0.05 \mathrm{mg} / \mathrm{kg}$ IV). Time of first analgesia required by the patient and total amount of analgesia consumption (Ketorolac and morphine) was collected and recorded at the end of the 24 postoperative hours.

Any postoperative complications was spotted and recorded, e.g. symptoms or signs of local anesthetic toxicity (tinnitus, perioral numbness, seizure) and Postoperative nausea and or vomiting (PONV) where intravenous metoclopramide $(10 \mathrm{mg})$ was given as a first line of treatment of vomiting. If not respond to metoclopramide; ondanseterone was given as a second line of treatment of vomiting. Patient satisfaction was assessed according to; no satisfaction, partial satisfaction and complete satisfaction.

\section{Statistical analysis:}

Recorded data were analyzed using the statistical package for social sciences, version 20.0 (SPSS Inc., Chicago, Illinois, USA). Quantitative data were expressed as mean \pm standard deviation (SD). Qualitative data were expressed as frequency and percentage. P-value was considered significant when $\mathrm{P}$-value < 0.05 . A one-way analysis of variance (ANOVA) was used when comparing between more than two means. Chi-square $\left(x^{2}\right)$ test of significance was used in order to compare proportions between qualitative parameters. 


\section{RESULTS}

According to demographic data (Age and Body weight), duration of surgery in minutes and type of surgery, There was no statistically significant difference (P-value $>0.05$ ) among the three groups (Table 1).

Table (1): Comparison between groups according to demographic data, type and duration of surgery

\begin{tabular}{|c|c|c|c|c|}
\hline $\begin{array}{l}\text { Groups } \\
\text { Demographic data }\end{array}$ & $\begin{array}{l}\text { (QLB) Group } \\
{[\mathbf{N}=30]}\end{array}$ & $\begin{array}{c}\text { (TAP) Group } \\
{[\mathbf{N}=30]}\end{array}$ & $\begin{array}{c}\text { Control Group } \\
{[\mathbf{N}=30]}\end{array}$ & p-value \\
\hline Age (years) & $39.96 \pm 7.70$ & $37.56 \pm 8.12$ & $38.76 \pm 9.41$ & $>0.05$ \\
\hline Body weight (kg) & $77.25 \pm 7.21$ & $75.62 \pm 6.78$ & $76.93 \pm 6.99$ & $>0.05$ \\
\hline $\begin{array}{l}\text { Duration of surgery } \\
\text { (min) }\end{array}$ & $48.20 \pm 12.98$ & $44.35 \pm 10.90$ & $46.28 \pm 11.94$ & $>0.05$ \\
\hline $\begin{array}{l}\text { Type of surgery } \\
\text { Inguinal hernia } \\
\text { Varicocele } \\
\text { Hydrocele }\end{array}$ & $\begin{array}{c}15(50.0 \%) \\
11(36.7 \%) \\
4(13.3 \%)\end{array}$ & $\begin{array}{c}19(63.3 \%) \\
8(26.7 \%) \\
3(10.0 \%)\end{array}$ & $\begin{array}{c}16(53.3 \%) \\
11(36.7 \%) \\
3(10.0 \%)\end{array}$ & $>0.05$ \\
\hline
\end{tabular}

The intra-operative heart rate from skin incision to after $90 \mathrm{~min}$ of surgery and postoperative heart rate from PACU till the end of the first 24 hours after the operation showed a statistically significant difference among the three groups (Tables 2 and 3).

Table (2): Comparison between groups according to intra-operative heart rate (beat/min.)

\begin{tabular}{|c|c|c|c|c|}
\hline $\begin{array}{l}\text { Heart rate } \\
\text { (beat/ min.) }\end{array}$ & $\begin{array}{c}\text { (QLB) Group } \\
{[\mathrm{N}=30]}\end{array}$ & $\begin{array}{c}\text { (TAP) Group } \\
{[\mathbf{N}=\mathbf{3 0}]}\end{array}$ & $\begin{array}{l}\text { Control Group } \\
{\left[\begin{array}{l}\mathbf{N}=\mathbf{3 0}]\end{array}\right.}\end{array}$ & p-value \\
\hline Before induction & $83.05 \pm 5.91$ & $84.61 \pm 6.34$ & $80.99 \pm 4.88$ & $>0.05$ \\
\hline At skin incision & $80.42 \pm 3.70$ & $85.23 \pm 4.38$ & $86.90 \pm 4.51 a$ & $<0.001$ \\
\hline After 15 min. & $76.11 \pm 3.57$ & $81.68 \pm 5.92 a$ & $83.79 \pm 5.23 a$ & $<0.001$ \\
\hline After 30 min. & $74.57 \pm 3.51$ & $77.65 \pm 10.76 a$ & $81.29 \pm 4.92 \mathrm{a}$ & 0.002 \\
\hline After 45 min. & $76.47 \pm 3.66$ & $80.06 \pm 7.83 a$ & $84.36 \pm 9.30 \mathrm{ab}$ & $<0.001$ \\
\hline After 60 min. & $76.52 \pm 2.82$ & $80.06 \pm 7.72 a$ & $84.50 \pm 6.86 a b$ & $<0.001$ \\
\hline After 75 min. & $76.47 \pm 5.84$ & $80.57 \pm 6.70 a$ & $85.75 \pm 6.24 a b$ & $<0.001$ \\
\hline After $90 \mathrm{~min}$. & $76.78 \pm 5.87$ & $80.90 \pm 6.73 a$ & $86.09 \pm 6.26 a b$ & $<0.001$ \\
\hline
\end{tabular}

a: significant difference with QLB group; b: significant difference with TAP group 
Table (3): Comparison between groups according to post-operative heart rate (beat/min.)

\begin{tabular}{|c|c|c|c|c|}
\hline $\begin{array}{l}\text { Heart rate } \\
\text { (beat } / \text { min.) }\end{array}$ & $\begin{array}{c}\text { (QLB) Group } \\
{[\mathbf{N}=30]}\end{array}$ & $\begin{array}{c}\text { (TAP) Group } \\
{[\mathbf{N}=30]}\end{array}$ & $\begin{array}{l}\text { Control Group } \\
\qquad[\mathbf{N}=\mathbf{3 0}]\end{array}$ & p-value \\
\hline At PACU. & $75.88 \pm 4.66$ & $78.41 \pm 6.82$ & $86.44 \pm 4.76 a b$ & $<0.001$ \\
\hline After 1 hour. & $74.27 \pm 3.02$ & $76.91 \pm 2.28$ & $85.65 \pm 3.49 a b$ & $<0.001$ \\
\hline After 2 hrs. & $74.12 \pm 2.79$ & $77.74 \pm 2.21 \mathrm{a}$ & 85.92 $\pm 3.09 a b$ & $<0.001$ \\
\hline After 3 hrs. & $74.27 \pm 3.04$ & $77.37 \pm 7.21 \mathrm{a}$ & $85.15 \pm 2.84 a b$ & $<0.001$ \\
\hline After 4 hrs. & $74.79 \pm 6.31$ & $77.12 \pm 5.60$ & $84.16 \pm 4.27 a b$ & $<0.001$ \\
\hline After 8 hrs. & $75.15 \pm 4.62$ & $78.41 \pm 3.92 a$ & $85.65 \pm 2.79 a b$ & $<0.001$ \\
\hline After 12 hrs. & $75.57 \pm 3.00$ & $79.96 \pm 2.30 a$ & $87.20 \pm 2.84 a b$ & $<0.001$ \\
\hline After 16 hrs. & $75.94 \pm 3.02$ & $80.35 \pm 2.31 a$ & $86.58 \pm 2.86 a b$ & $<0.001$ \\
\hline After 24 hrs. & $77.46 \pm 3.08$ & $81.96 \pm 2.36 a$ & $88.31 \pm 2.92 a b$ & $<0.001$ \\
\hline
\end{tabular}

a: significant difference with QLB group; b: significant difference with TAP group

The intra-operative mean arterial blood pressure from skin incision to after $90 \mathrm{~min}$ of surgery and postoperative mean arterial blood pressure from PACU till the end of the first 24 hours after the operation showed a statistically significant difference among the three groups (Tables 4 and 5).

Table(4): Comparison between groups according to intra-operative mean arterial bloo pressure (mmHg)

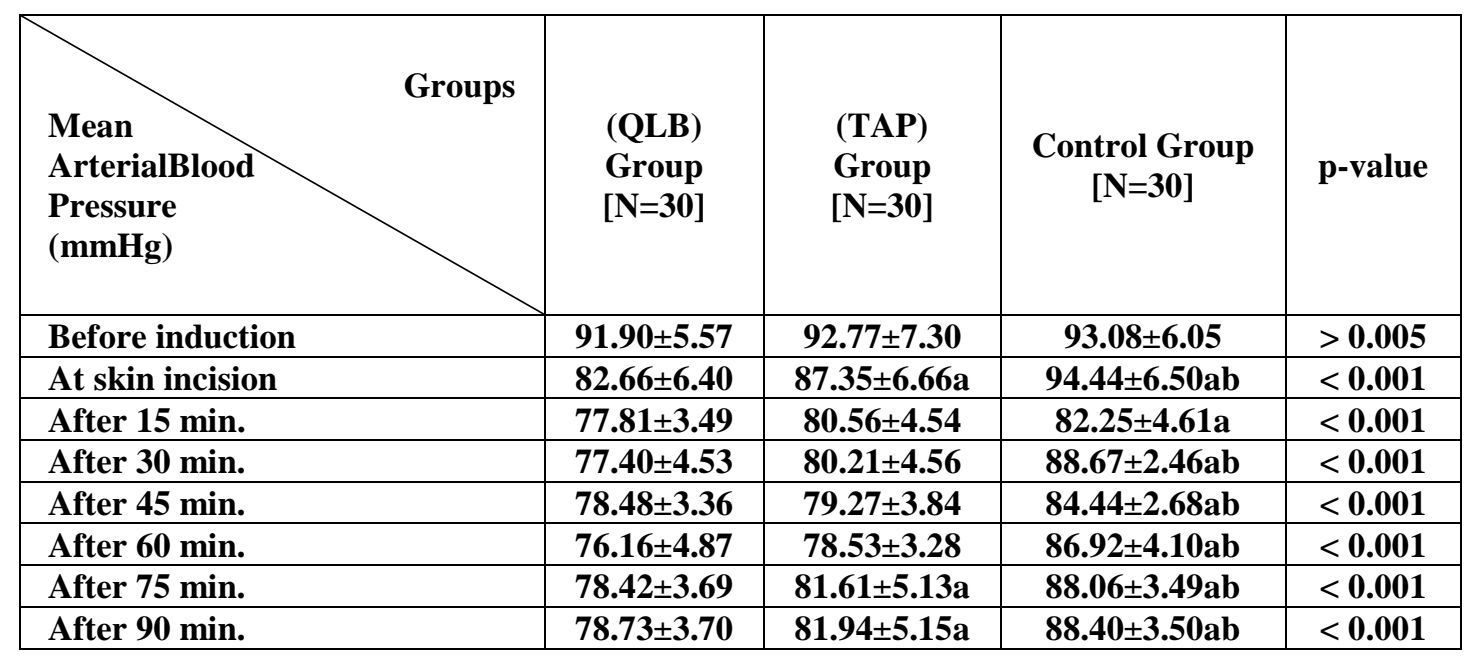

a: significant difference with QLB group; b: significant difference with TAP group 
Table (5): Comparison between groups according to post-operative mean arterial blood pressure (mmHg)

\begin{tabular}{|c|c|c|c|c|}
\hline $\begin{array}{l}\text { Mean } \\
\text { Arterial } \\
\text { Blood Pressure } \\
(\mathrm{mmHg})\end{array}$ & $\begin{array}{l}(\mathrm{QLB}) \\
\text { Group } \\
{[\mathbf{N}=30]}\end{array}$ & $\begin{array}{l}\text { (TAP) } \\
\text { Group } \\
{[\mathbf{N}=30]}\end{array}$ & $\begin{array}{c}\text { Control } \\
\text { Group } \\
{[\mathbf{N}=30]}\end{array}$ & p-value \\
\hline At PACU. & $80.30 \pm 3.78$ & $83.56 \pm 5.25 a$ & $90.17 \pm 3.57 a b$ & $<0.001$ \\
\hline After 1 hour. & $79.10 \pm 3.73$ & $82.32 \pm 5.17 a$ & $88.83 \pm 3.51 a b$ & $<0.001$ \\
\hline After 2 hrs. & $78.71 \pm 3.71$ & $81.92 \pm 5.14 a$ & $88.38 \pm 3.50 a b$ & $<0.001$ \\
\hline After 3 hrs. & $78.40 \pm 3.69$ & $81.58 \pm 5.12 a$ & $88.03 \pm 3.49 a b$ & $<0.001$ \\
\hline After 4 hrs. & $76.15 \pm 4.86$ & $78.51 \pm 3.29 a$ & $86.90 \pm 4.10 \mathrm{ab}$ & $<0.001$ \\
\hline After 8 hrs. & $78.46 \pm 3.36$ & $79.25 \pm 3.83$ & $84.42 \pm 2.13 \mathrm{ab}$ & $<0.001$ \\
\hline After 12 hrs. & $77.37 \pm 4.53$ & $82.26 \pm 4.56 a$ & $82.47 \pm 2.46 \mathrm{a}$ & $<0.001$ \\
\hline After $16 \mathrm{hrs}$. & $77.79 \pm 3.49$ & $81.59 \pm 4.54 a$ & $83.29 \pm 4.61 a$ & $<0.001$ \\
\hline After 24 hrs. & $79.35 \pm 3.56$ & $83.22 \pm 4.63 a$ & $84.96 \pm 4.70 a$ & $<0.001$ \\
\hline
\end{tabular}

\section{Post HOC:}

a: significant difference with QLB group; b: significant difference with TAP group

Postoperative measurements of respiratory rate showed a statistically significant difference among the three groups from PACU till the end of the first
24 hours after the operation; where respiratory rate was higher in control group than TAP group than QLB group (Table 6).

Table (6): Comparison between groups according to post-operative respiratory rate (breath/min.)

\begin{tabular}{|c|c|c|c|c|}
\hline $\begin{array}{l}\text { Respiratory } \\
\text { Rate } \\
\text { (Breath/min.) }\end{array}$ & $\begin{array}{l}(\mathrm{QLB}) \\
\text { Group } \\
{[\mathbf{N}=\mathbf{3 0}]}\end{array}$ & $\begin{array}{l}\text { (TAP) } \\
\text { Group } \\
{[\mathbf{N}=30]}\end{array}$ & $\begin{array}{c}\text { Control } \\
\text { Group } \\
{[\mathbf{N}=\mathbf{3 0}]}\end{array}$ & $\begin{array}{c}\text { p- } \\
\text { value }\end{array}$ \\
\hline At PACU. & $12.22 \pm 1.19$ & $14.70 \pm 1.24 a$ & $20.14 \pm 1.95 a b$ & $<0.001$ \\
\hline After 1 Hour. & $12.22 \pm 0.54$ & $13.14 \pm 1.04 a$ & $16.77 \pm 1.35 \mathrm{ab}$ & $<0.001$ \\
\hline After 2 hrs. & $12.42 \pm 0.28$ & $12.52 \pm 0.41$ & $16.87 \pm 1.14 a b$ & $<0.001$ \\
\hline After 3 hrs. & $12.52 \pm 0.23$ & $12.63 \pm 1.45$ & $15.84 \pm 2.51 \mathrm{ab}$ & $<0.001$ \\
\hline After 4 hrs. & $12.63 \pm 1.04$ & $12.42 \pm 1.14$ & $15.32 \pm 1.14 a b$ & $<0.001$ \\
\hline After 8 hrs. & $12.42 \pm 2.38$ & $12.42 \pm 1.14$ & $15.21 \pm 0.52 \mathrm{ab}$ & $<0.001$ \\
\hline After $12 \mathrm{hrs}$. & $12.36 \pm 2.39$ & $12.69 \pm 1.14$ & $14.26 \pm 0.53 \mathrm{ab}$ & $<0.001$ \\
\hline After $16 \mathrm{hrs}$. & $12.38 \pm 2.40$ & $12.85 \pm 1.15$ & $14.22 \pm 0.53 \mathrm{ab}$ & $<0.001$ \\
\hline After 24 hrs. & $12.63 \pm 2.45$ & $13.11 \pm 1.17$ & $14.50 \pm 0.54 a b$ & $<0.001$ \\
\hline
\end{tabular}

a: significant difference with QLB group; b: significant difference with TAP group

Onset of sensory block at T10 ranged from 9-15 in TAP group and from 13-19 minutes in QLB group with mean values of $\quad 12.16 \pm 3.55$ and $16.60 \pm 3.58$ respectively. TAP block is significantly earlier than QLB regarding the onset of sensory blockade at T10, p <0.001.
There was also statistically significant difference among the three groups in terms of postoperative VAS after the operation. The VAS measurements in QLB group were lower than in TAP group, and those in TAP group were lower than in control group, with p-value $<0.05$. 
There were statistically significant differences among the three groups in terms of the time needed to give the first dose of rescue analgesia after the operation. The time in QLB group was longer than in TAP group, and that in TAP group was longer than in control group, with $\mathrm{p}$-value $<0.005$, which was considered significant, The collected data about Ketorolac and morphine consumed in the first 24 hours also shows statistically significant difference among the three groups (Table 7).

Table (7): Average consumption of analgesia in the first 24 hours (mg)

\begin{tabular}{|l|c|c|c|c|}
\hline Groups & $\begin{array}{c}\text { (QLB) Group } \\
{[\mathrm{N}=30]}\end{array}$ & $\begin{array}{c}\text { (TAP) Group } \\
{[\mathrm{N}=30]}\end{array}$ & $\begin{array}{c}\text { Control Group } \\
{[\mathrm{N}=30]}\end{array}$ & -value \\
\hline Time to first dose (min.) & $\mathbf{1 8 7 . 6 6} \pm 23.84$ & $\mathbf{1 2 8 . 0 7} \pm \mathbf{1 5 . 2 5 a}$ & $\mathbf{1 5 . 1 5} \pm 5.45 \mathrm{ab}$ & $<0.001$ \\
\hline Ketorolac consumption $(\mathrm{mg})$ & $\mathbf{3 1 . 0 2} \pm 23.78$ & $\mathbf{5 1 . 7 0} \pm 18.61 \mathrm{a}$ & $\mathbf{9 3 . 0 6} \pm 25.85 \mathrm{ab}$ & $<0.001$ \\
\hline Morphine consumption $(\mathrm{mg})$ & $\mathbf{3 . 2 1} \pm 1.85$ & $\mathbf{8 . 8 6} \pm 2.88 \mathrm{a}$ & $\mathbf{1 6 . 2 2} \pm 3.63 \mathrm{ab}$ & $<0.001$ \\
\hline
\end{tabular}

a: significant difference with QLB group; b: significant difference with TAP group

There were no recorded cases in QLB group and TAP group in terms of postoperative nausea and vomiting with no statistically significance. However, there were 6 cases recorded in control group with statistically difference between the two studied groups and control group, with p-value $<0.05$, which considered significant. 4 patients treated by IV metoclopramide (10 $\mathrm{mg})$ only, and 2 patients suffered from PONV that not responded only to IV metoclopramide (10 $\mathrm{mg}$ ) and responded to IV ondansetron (4mg).

As regard the patient satisfaction, there was a statistically highly significant of patient satisfaction $(\mathrm{P}<0.001)$ where there were 24 cases (80\%) in QLB group, 18 cases $(60 \%)$ in TAP group recorded complete patient satisfaction compared to 2 cases $(6.7 \%)$ in the control group (Table 8).

Table (8): Comparison between groups according to patient satisfaction score (number of patients and \%)

\begin{tabular}{|c|c|c|c|c|c|c|c|}
\hline \multirow[b]{2}{*}{ Patient Satisfaction } & \multicolumn{2}{|c|}{$\begin{array}{c}\text { (QLB) Group } \\
{[N=30]}\end{array}$} & \multicolumn{2}{|c|}{$\begin{array}{c}\text { (TAP) Group } \\
{[\mathbf{N}=\mathbf{3 0}]}\end{array}$} & \multicolumn{2}{|c|}{$\begin{array}{c}\text { Control Group } \\
{[\mathrm{N}=\mathbf{3 0}]}\end{array}$} & p-value \\
\hline & No. & $\%$ & No. & $\%$ & No. & $\%$ & \multirow{4}{*}{$<0.001$} \\
\hline Complete satisfaction & 24 & 80 & 18 & 60 & 2 & 6.7 & \\
\hline Partial satisfaction & 4 & 13.3 & 10 & 33.3 & 13 & 43.3 & \\
\hline No satisfaction & 2 & 6.7 & 2 & 6.7 & 15 & 50 & \\
\hline
\end{tabular}

\section{DISCUSSION}

The current study measured and compared intraoperative hemodynamics in the form of heart rate and mean arterial blood pressure. The measurements in QLB group were lower than in TAP group, and those in TAP group were lower than in control group, which demonstrated that QLB was the most effective analgesic modality, and that TAP block was more effective than general anesthesia alone. The study also measured and compared postoperative heart rate, mean arterial blood pressure and respiratory rate in the first 24 hours after the operation. The measurements in QLB group were lower 
than in TAP group, and those in TAP group were lower than in control group, which also demonstrated that QLB was the most effective analgesic modality, and that TAP block was more effective than intravenous analgesics alone.

The current results are in agreement with the results of Shafeek and Coworkers (2018) that compared the analgesic efficacy of ultrasound-guided transmuscular quadratus lumborum block with transverses abdominis plane (TAP) block and intravenous opioid drugs during laparoscopic bariatric surgery and in the early postoperative period. They found a statistically significant difference between groups in intra-operative heart rate and mean arterial blood pressure, from after $30 \mathrm{~min}$. to after $120 \mathrm{~min}$. of surgery and also a statistically significant difference between groups in post-operative heart rate and mean arterial blood pressure from 0 min. to 8 hrs. after the operation.

In the current study, the effect of QLB and TAP block in preventing the variability in the postoperative hemodynamics and respiratory rate was the result of reduction in the incidence and severity of postoperative pain, which was demonstrated by comparing visual analogue scale (VAS) measurements among the three groups. VAS measurements in QLB group were lower than in TAP group, and those in TAP group were lower than in control group. The current study showed that the time needed to give the first dose of systemic analgesia after the operation was longer in QLB group than in TAP group, and that in TAP group was longer than in control group. It also showed that the number of required analgesia in QLB group was less than in TAP group, and that in TAP group was less than in control group. The total amount of analgesia required in QLB group was less than in TAP group, and that in TAP group was less than in control group. The patients of control group had the highest pain scores, were the first to ask for rescue analgesia, and consumed the highest amount of analgesia; therefore, they had the highest total analgesic consumption in the first 24 hours postoperatively in comparison to patients of the other two groups. On the contrary, the patients of QLB group had the lowest pain scores, were the last to call for intravenous analgesia, and consumed the lowest total dose of systemic analgesia.

Similarly, Sukhyanti and Kirti (2017) performed posterior QLB in the supine position for postoperative analgesia in patients undergoing cesarean section. The results of current study agreed with their findings. Compared to TAP block, QLB provided widespread analgesia of longer duration. The sensory levels obtained by QLB were T7 and T12 dermatomes, whereas TAP block affected T10 and T12 dermatomes. This could be explained by local anesthetic spread either in the thoracolumbar plane or into the paravertebral space. The duration of analgesia after QLB exceeded 24 hours, and was significantly longer than that for TAP block.

Garg and Coworkers (2017) reported a case of a 22-year-old male patient with Prune belly syndrome presented for right high inguinal orchiectomy. They used unilateral QL block after general anesthesia for pain control. The patient was comfortable, pain free and did not require any further analgesia in the 
postoperative period. This case report highlights the use of QLB for postoperative analgesia in major abdominal surgery, especially where epidural is contraindicated or difficult. This new QL block has the advantage of providing wider sensory block from T6 to L1 and thus has an evolving role in opioid free anesthesia.

The current study showed that TAP block was highly significantly earlier than QLB regarding the onset of sensory blockade at T10, where the onset of sensory block at T10 ranged from 6-12 and from 9-18 minutes in TAP group and QLB group respectively.

Results of this current study showed that patient satisfaction scores were significantly higher in QL group than in TAP group and control group. The reported postoperative complications as nausea and vomiting were due to the systemic use of analgesics and were mostly among control group rather than the other two groups. The reason for this could be due to the higher analgesic requirements among control group rather than among the other two groups.

The current study agreed with the results of Ilana and Coworkers (2017). They performed bilateral QLB in three women who received a spinal anesthesia for a cesarean delivery and evaluated their postoperative opioid consumption and patient satisfaction. They found that there was no additional opioid consumption during the first 24 hours after the block. VAS for pain was less than six for the first 24 hours. Women were all very satisfied with the quality of pain relief.

Öksüz and Coworkers (2017) compared the QLB and TAP block for postoperative pain relief after lower abdominal surgery in children. The results of their study showed that the QL block provided more effective pain relief compared with the TAP block and did not have any adverse effects, the number of patients who required analgesia in the first 24 hours postoperatively was significantly lower in the quadratus lumborum block group. In the quadratus lumborum block group, the postoperative 30-minute and 1, 2, 4, 6, 12, and 24 hour FLACC scores were lower compared with those of the transverses abdominis plane block group, Parent satisfaction scores were higher in the quadratus lumborum block group.

\section{CONCLUSION}

Ultrasound guided quadratus
lumborum and transverses abdominis
plane blocks provided effective modality
for control of postoperative pain
associated with unilateral inguinal
surgeries. Ultrasound guided quadratus
lumborum block was superior to
ultrasound guided transverses abdominis
plane block for control of postoperative
pain in unilateral inguinal surgeries in
terms of pain scores, duration of analgesia
and total analgesic consumption.
However, TAP block still technically
easier than QL block. Both ultrasound
guided quadratus lumborum and
transverses abdominis plane blocks were
not associated with significant side effects
in patients undergoing unilateral inguinal
surgeries. Patients satisfaction was good
in both groups but with better in quadratus
lumborum group.

\section{RECOMMENDATIONS}

Ultrasound guided quadratus lumborum block anterior approach can be 
used as a part of multimodal analgesic strategy for patients undergoing unilateral inguinal surgeries. Further studies should be conducted to compare between different approaches of quadratus lumborum block in patients undergoing lower abdominal surgeries in future studies; This may show which approach is better regarding pain control. Further studies also recommended using ultrasound guided quadratus lumborum blocks in different volumes in patients to determine the optimum volume (dose). Adding adjuvants to LA as fentanyl, dexmedetomidine, dexamethasone and others and their impact on efficacy and duration of QL block also recommended in future study. Use of bilateral quadratus lumborum block in midline surgeries and the use of continuous catheters for continuous analgesia can be studied in the future.

\section{REFERENCES}

1. Blanco R, Ansari T and Girgis E (2015): Quadratus lumborum block for postoperative pain after caesarean section: a randomised controlled trial. European Journal of Anaesthesiology (EJA), 32(11): 812-818.

2. Børglum $J$ and Jensen $K$ (2012): Abdominal surgery: advances in the use of ultrasound-guided truncal blocks for perioperative pain management. Abdominal Surgery. Rijeka, Croatia: InTech, 69-94.

3. Chin KJ, McDonnell JG, Carvalho B, Sharkey A, Pawa A and Gadsden J (2017): Essentials of Our Current Understanding: Abdominal Wall Blocks. Regional Anesthesia and Acute Pain, 42:133-183.

4. El-Sharkawy H (2017): Quadratus lumborum blocks. Advances in Anesthesia Journal, 35( 1): 145-157.

5. Garg C, Khanna S and Mehta $Y$ (2017): Quadratus lumborum block for post-operative pain relief in patient with Prune belly syndrome. Indian Journal of Anesthesia, 61(10):840-2.

6. Ilana S, Fatemah Q and Shalini D (2017): Ultrasound guided Quadratus Lumborum block for analgesia after cesarean delivery: case series. Brazilian Journal of Anesthesiology (English Edition), 67(4): 418421.

7. Öksüz G, Bilal B, Gürkan Y, Urfalioğlu A, Arslan M, Gişi G. and Öksüz H (2017): Quadratus Lumborum Block Versus Transversus Abdominis Plane Block in Children Undergoing Low Abdominal Surgery: A Randomized Controlled Trial. Regional Anesthesia and Pain Medicine, 42 (5): $1-6$.

8. Owen DJ, Harrod I, Ford J, Luckas M, and Gudimetla V (2011): The surgical transversus abdominis plane block - a novel approach for performing an established technique. BJOG: An International Journal of Obstetrics \& Gynaecology, 118(1): 24-27.

9. Owen M, Lorgelly $P$ and Serpell M (2010): Chronic pain following donor nephrectomy a study of the incidence, nature and impact of chronic post-nephrectomy pain. European Journal of Pain, 14:732-73.

10. Shafeek A, Gomaa G, Abd EIMalek F, Khaled H. and Doaa $M$ (2018): A Comparative Study between Ultrasound Guided Quadratus Lumborum Block Versus Ultrasound Guided Transversus Abdominis Plane Block in Laparoscopic Bariatric Surgery. Egyptian Journal of Hospital Medicine, 70(12): 2090-2099.

11. Sukhyanti $K$ and Kirti NS (2017): Quadratus lumborum block for postcaesarean analgesia. Indian Journal of Anesthesia, 61(4):364-5.

12. Ueshima $H$, Kubo $K$, Sakamoto $S$, Okamoto A, Onose A, Hatano K, Masuzawa $M$ and Shingu K (2013): A case of the transversus abdominis plane block in a super obese patient using a convex probe. Masui the Japanese Journal of Anesthesiology, 62(4):439-41. 


\section{دراسة مقارنة بين التخدير الموضعي للعضلة المربعة القطنية} باستخدام الموجات فوق الصوتية والتخدير الموضعي للعضلة البطنية المستعرضة باستخدام الموجات فوق الصوتية وأثره في تسكين آلام مابعد الجراحة في المرضى الأين يخضعون للجراحات الأربية في ناحية واحدة

على محمد على إسـماعيل، طــارق عـبـدالسـلام سليم موسى، عصام شفيق محمد عبدالوهاب، مصطفى محمد محمد السيد

قسم التخدير والعناية المركزة، كلية الطب بنين، القاهرة، جامعة الأزهر

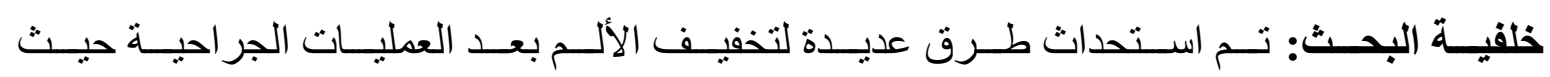

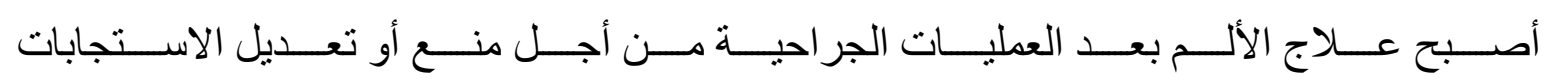
الفسيولوجية للإجهاد و الضغط العصبي عنصر ا أساسيا في علم التخدير.

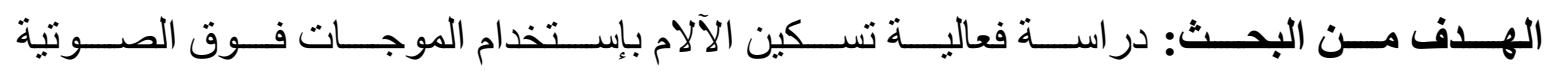

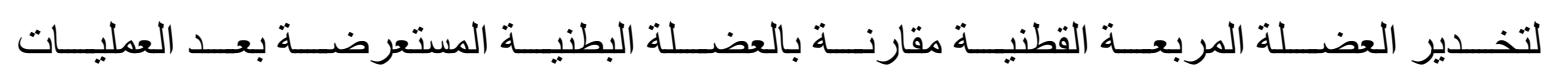

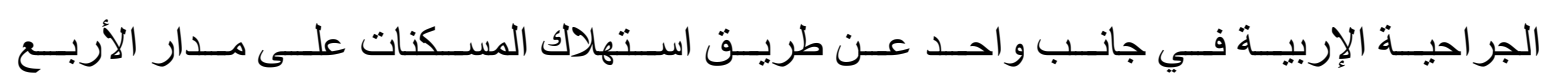
و العشرين ساعة الأولي.

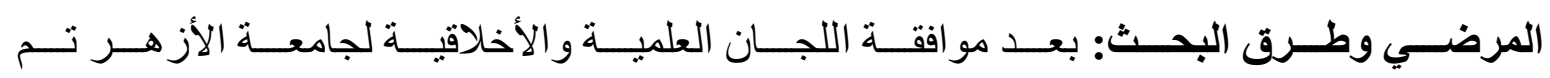

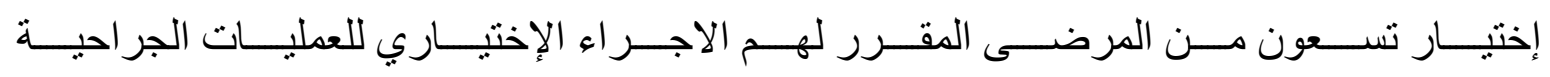

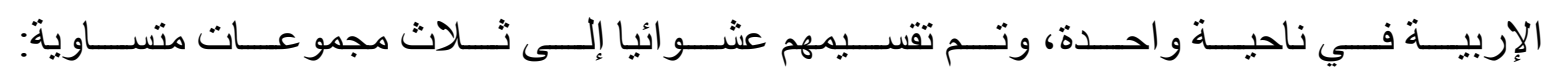

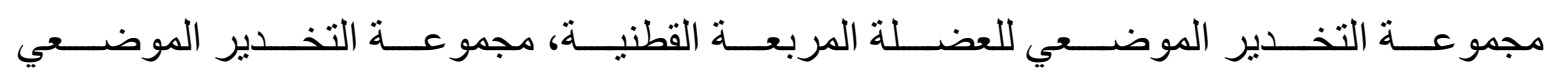

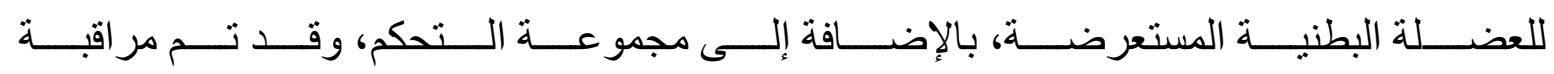

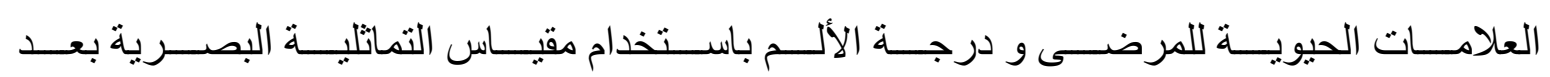

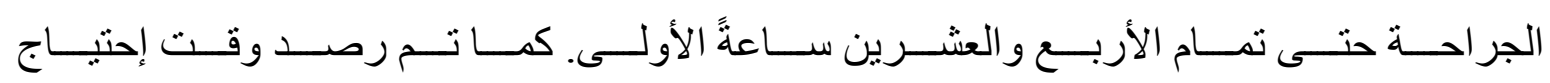

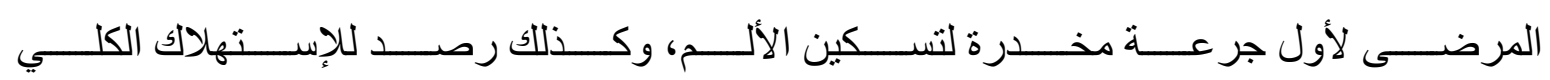

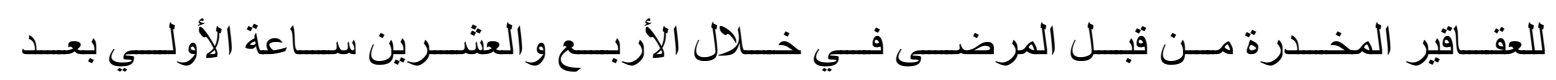




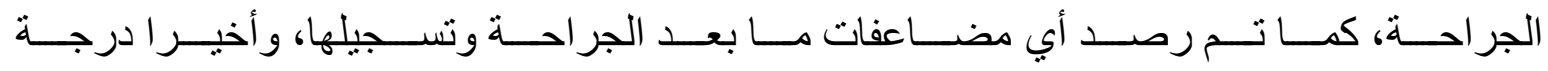
رضى المرضى، ثم تم تسجيل النتائج وتحليلها إحصائيا.

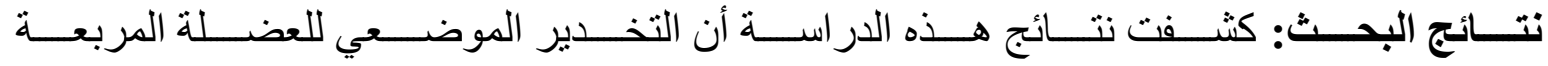

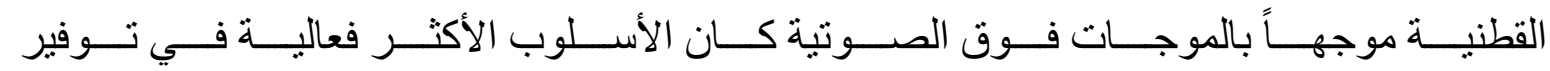

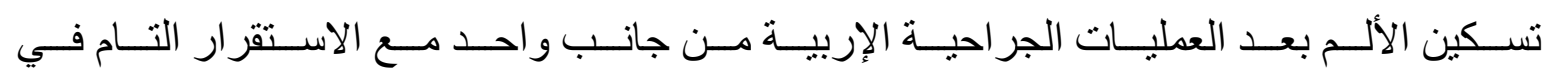

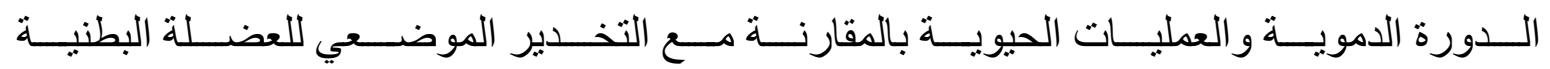

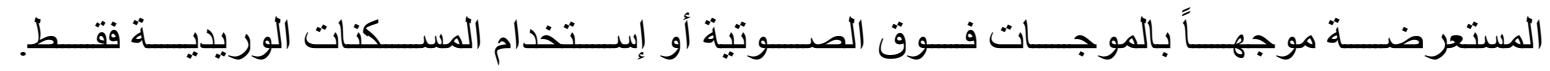

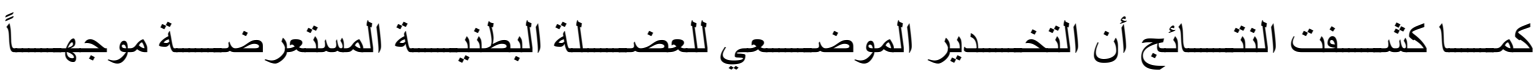

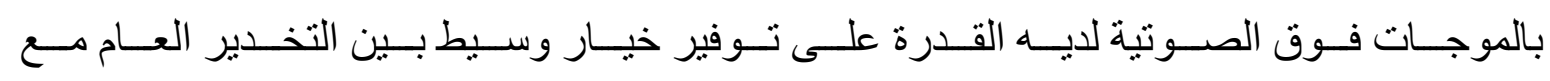

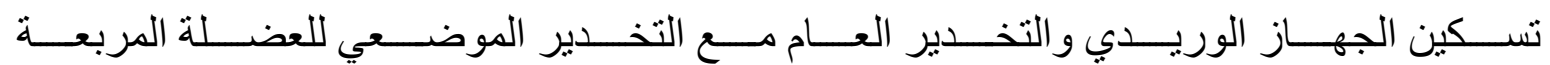

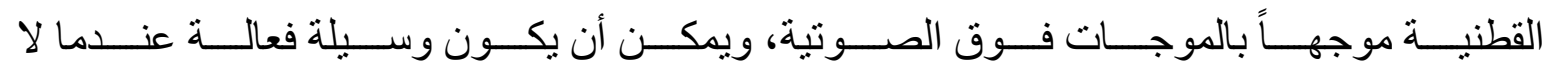

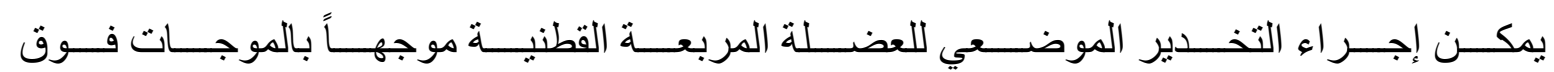
الصوتية.

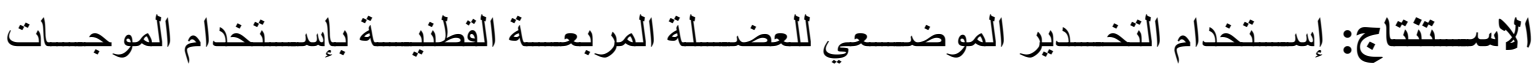

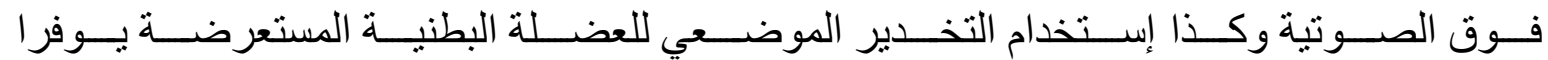

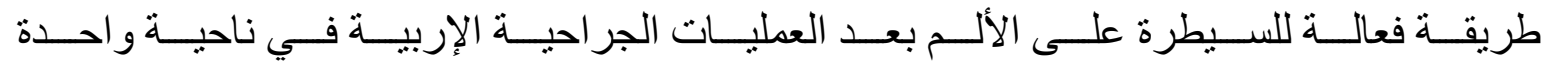

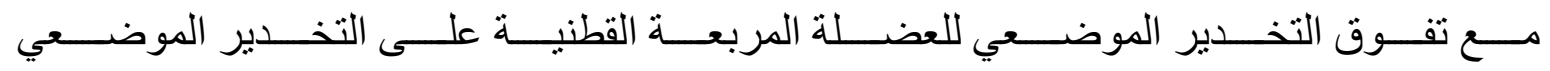

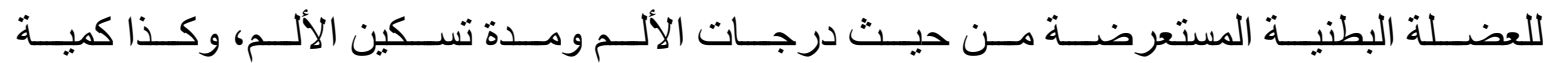

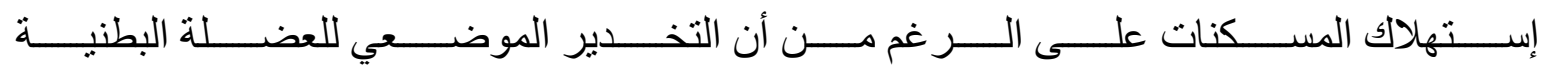

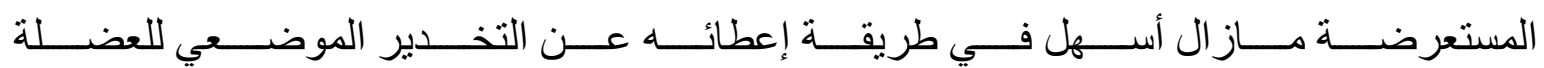
المربعة القطنية. 